of only one person, Dr Eisen. Clearly, others well outside the acquaintences of the authors should have been included Moreover, the charges to the committees were inadequate, the reports were made many months later and years passed before they became public. Nevertheless, to his credit, Eisen has recently corrected an important misunderstanding in his original report (Nature 352, 101; 1991). Finally, the universities did little to protect the rights of the whistleblower.

Once the National Institutes of Health (NIH) took up the investigation, they too faltered. The first NIH investigating committee had to be reconstituted to remove two long-time collaborators of Baltimore, thereby losing valuable time and raising the suspicion of incomplete objectivity. This committee then took the questionable step of accepting supplementary data provided by Imanishi-Kari in lieu of that which was disputed in the original paper. But this action had to be reversed when the Secret Service, brought in at the initiative of Congressman Dingell, presented evidence that some of the supplementary data were compiled after the publication of the Cell paper. Meanwhile, Dingell initiated congressional hearings. The first of these probably erred in not having any of the authors testify, but the two subsequent hearings did afford a broad disclosure of all sides of the controversery, exposing a number of points missed by the NIH committee. The newly constituted Office of Scientific Integrity created a panel in the autumn of 1989: and after two years' work it has produced in its draft report the most comprehensive examination that the situation requires.

The scientific community itself has not been very active over these five years. In the first two congressional hearings, a number of scientists were aroused by fears, initiated in part by Baltimore, that inappropriate congressional interference with science was underway, but this has not continued as the seriousness of the charges of questionable behaviour rose. And the National Academy of Sciences did appoint a panel on scientific conduct early in 1991 to recommend procedures for improved self-policing in science but it has not yet reported.

Whatever the faults and virtues of the procedures applied in this case, it is clear that they provide little guidance for the future. Cases of alledged misconduct can not be handled by congressional hearing, which would limit examination to about one case per year. Nor can recourse be made to the courts where the expense and time consumed could not be afforded. It remains to review the several cases where local academic committees have resolved such cases promptly and effectively and see how this method can be strengthened and augmented by special oversight committees such as the OSI might appoint.

But the essence of change must come within the scientific community by its reassertion of its ability to police itself. In contrast to the pattern of behaviour seen in this case, the scientists making up the OSI panel praised the actions of the whist leblower, Dr O'Toole, as "heroic in many respects" and went on to state that "she deserves the approbation and gratitude of the scientific community for her courage and dedication to the belief that truth in science matters". Yet one sees little other evidence of the scientific community expressing itself accordingly. Unless it does so eventually, its silence can be interpreted as condoning the standards of research and reporting embodied in the Weaver et al. paper.

This challenge to readdress the fundamental tenets of acceptable behaviour in science comes at a time when the traditions of the scientific enterprise are under new threats arising from new stresses and temptations. The growth of the enterprise itself with its accompanying bureaucracy, the near cut-throat competition for grants, the possible corruption, on occasion, of peer review, the growing number of cases of deception in scientific papers, scientists' acquiescence in the increasing avoidance of meaningful review in direct congressional grants for research buildings and projects - all these contribute to the pressure to compromise and erode the high principles of the past. As a result, the scientific community may already be experiencing a gradual departure from the traditional scientific standards; this could be abetted by condoning the behaviour seen in this present case. In this way we risk sliding down toward the standards of some other professions where the validity of action is decided by whether one can get away with it. For science to drift toward such a course would be fatal - not only to itself and the inspiration which carries it forward, but to the public trust which is its provider.

Paul Doty is Mallinckrodt Professor of Biochemistry Emeritus, Harvard University, Boston, Massachusetts, USA

\title{
Dissent on forensic evidence
}

Below we republish extracts from the "minority opinion" by Drs Hugh 0 . McDevitt and Ursula Storb that accompanied the draft report on Weaver et al. by the US NIH's Office of Scientific Integrity.

AFTER noting that they find the sections of the report dealing with the substance of the disputed paper and its internal inconsistencies "accurate and complete to the best of our recollection", the authors discuss the use of forensic evidence in later sections of the draft report "with which we are in serious disagreement".

"In section IV. A statistical analysis of transcribed gamma counter counts reveals that in many instances, handwritten counts do not show a normal Poisson distribution, and display considerable 'spikiness'. We do not agree with either the prominence given the results of these statistical analyses, nor with the conclusions based on these analyses.

"Similarly, in section IV.B, marked periodicity of the counts is found not to be in agreement with a sampling of hybridoma wells which it is purported to represent. However, while this suggests that data from an unrelated experiment were used for pages 102-107 [of the notebook submitted to the Dingell Committee] we cannot accept the statistical evidence as proof. "The second line of evidence presented in sections IV.A \& B is much more convincing. The forensic analysis concerning the chemical composition of ink on counter tapes found on [some notebook] pages ... indicates that a full match for these tapes is not found anywhere after April 1982 in any of the laboratory notebooks used by individuals using the same counter.

"Initially, this might have been explained by an inadequate sampling of laboratory notebooks of other individuals using the counter in question. However, at the panel's request, numerous additional notebooks were obtained, and it now seems likely that a substantial majority has been examined. Despite this extensive sampling, no other laboratory notebooks had tapes with a full match dated later than April 1982.

"Unfortunately, the panel was not given access to the actual chromatograms which led the Secret Service to make the conclusions referred to above. Examination of chromatographs of similar inks from similar analyses, as well as other available techniques (if chromatographic analysis fails to distinguish two inks) indicates that the methods used are certainly capable of determining identity or non-identity of two ink mixtures. Ultimately, the actual chromatograms need to be examined.

"However, with this reservation, the findings as stated, combined with the other inconsistencies found on the pages referred to above, make it seem likely that the data on these pages are not the result of experiments performed at or near the time stated, but in fact, are data from other experiments performed as much as three years earlier.

"The significance of these data, their relevance to the initial and subsequent investigations, and the corresponding reasons why these data are legitimate targets for the present investigation, are all well described in the report, and we are in agreement with that description. 